\title{
An Instrument for Use in Squint Operations
}

\begin{tabular}{|l|l|l|}
\hline G.J. & du Marchie & Sarvaas \\
\hline
\end{tabular}

Nederlandsch Gasthuis voor Ooglijders, Utrecht [Dir.: Prof. Dr. H. J. M. Weve]

In the resection and advancement of an extraocular muscle the placing of the suture in the correct position sometimes gives rise to difficulties. One must exert traction upon the muscle in order to get it free enough to place the suture without obstruction from the conjunctiva. The alternate pulling and letting go of the muscle is painful, giving rise to restlessness in the patient.

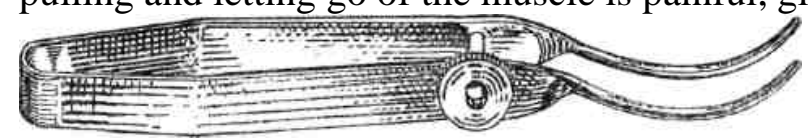

In order to diminish this, I recommend the following instrument 1. It is a strong springed forceps with a fine grooved, curved

1 The instrument can be secured from firm Bietveld, Waterloplein 99, Amsterdam.

duMarchic S a r v a a s, An Instrument for Use in Squint Operations 123

sound at either extremity. A screw makes it possible to set the sounds at the desired distance, which can then be measured.

The screw prevents the forceps springing open, but it is always possible to close the instrument completely.
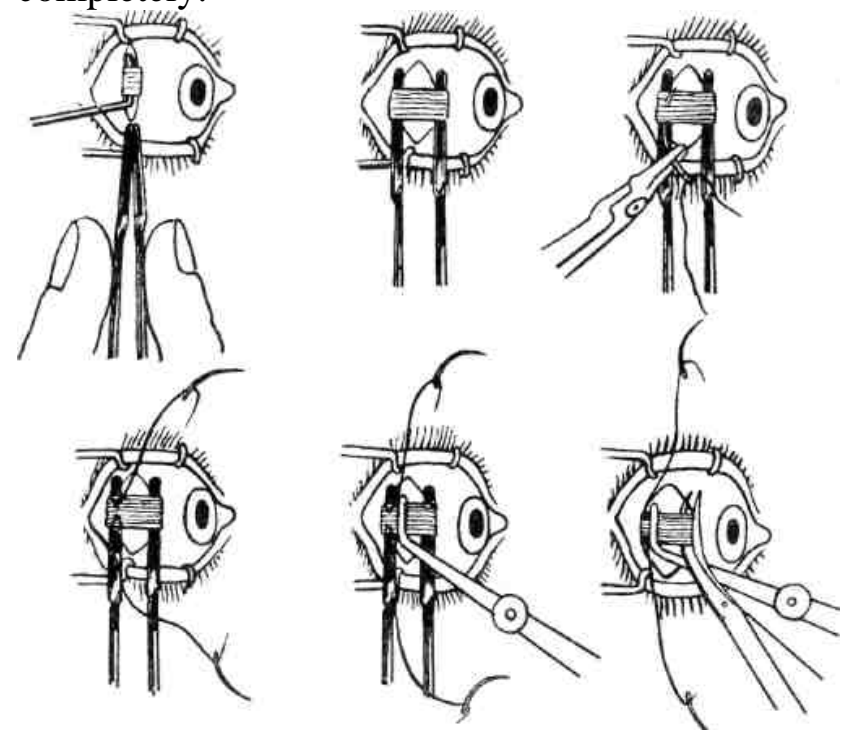

The method of operation is as follows:

Conjunctival incision, free-preparation of the muscle. Under guidance of a squint hook the closed forceps is introduced under the muscle. The conjunctiva and Tenon's capsule are pushed aside and the muscle well exposed. It is now not necessary to pull any more on the muscle. One can now insert the thread easily in the proper place over the grooved sound. After suturing it is 
necessary to apply muscle forceps to secure the thread. After excising the necessary piece of muscle the operation continues in the ordinary manner.

The advantages of this method are:

The application of the muscle suture is very easy.

The suturing is almost painless and the patient remains calm.

The regulating and measuring of the piece of muscle for resection is simple and not timeconsuming.

The two grooved sounds make it possible to use the forceps both right and left.

Ophthalmologica, Vol. 123, Nr. 2 (Februar 1952)

in

(From the Ophthalmological Department [Head: I. Aszalós, M.D.] of the Municipal Hospital, Baja, Hungary [Director: Prof. E. Burg].)

Marginofixator. A New Instrument for Holding the Lid Margin in Position.

By L. BAGÓCZKY.

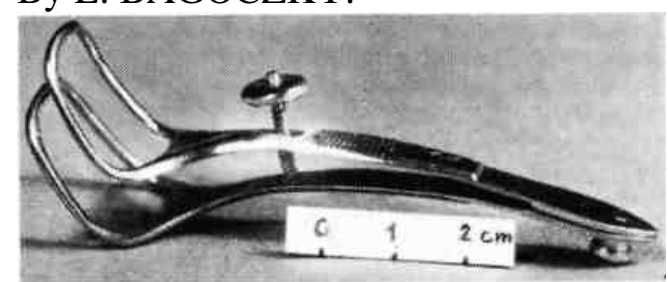

In operations on the lids and the edges of the lids, fixation and accessibility of the operative area are of utmost importance. For this purpose blepharostats (Elschnig, Desmarres, Kuhnt), Olálïs forceps and other instruments have been available. In operations on the lid margins we have found an instrument of our design to be more useful than those afore-mentioned. Its description is given below.

The "Marginofixator" (see photograph) consists of two similar halves, a lower and an upper one. Each of these has a fenestrated blade and a handle which are slightly curved and held together at the ends by a small screw. The other screw to be seen on the handle serves the same purpose as that on a blepharostat. The blades, which are shaped so as to fit the eyeball, are bent at about two-thirds of the distance from their rounded ends at right angles.

For operations on either surface of the lid or on the lid margin, always the lower blade is inserted under the lid, the clamping screw tightened and, if necessary, the handle working as a secondclass lever, raised until the desired operative position is obtained.

The instrument can be used

in all operations on the margins of the eyelids;

in all operations on either surface of the eyelid; 